\title{
Assessing Physical-spatial Impacts of Superblocks and Inner Urban Historical Fabrics Adjacency,Case study analysis of Great Mosque historical context of Shahre-Kord
}

\author{
Milad HeidariSoureshjani
}

\begin{abstract}
Inner urban historical fabrics are the symbol of various cities' identity. Sustainability of these textures is directly depended on physical/spatial conservation. Today's cities are normally made of a combination of traditional fabric with fine grain and modern textures with coarse grain, from typology point of view. An emerging typology feature of recent fabrics is known as superblock with the size of double or multiple of a current urban block, in which roadway traffic is confined. Recently in adjacency of Shahre-kord Great mosque historical fabric, compound of few coarse grain buildings along with inner areas confined for vehicles entrance, has led to shape a superblock. It seems that the superblock resulted in degradation of nearby historical fabric from various aspects. The paper explores physical/spatial effects of the issue. The main method used in this paper is a descriptive analysis relying on observation along with network analysis software "Pajek" and space syntax method, relatively comprehensive survey was made through the context to give some indication about the effects. Results has revealed that various physical factors, have affected pedestrian behavior in public spaces and the superblock is changing physical/spatial structure of the Great mosque fabric.
\end{abstract}

Index Terms - Sustainability, historical preservation, superblock, urban typology, Shahrekord

\section{INTRODUCTION}

Studying the form of contemporary cities and their effects of different aspects on neighboring fabric is accounted as those knowledge, every urban designer should be familiar with $\left[{ }^{1}\right]$ Today cities are compound of two simple concepts from urban form point of view:

- Traditional city: an area commonly with fine grain fabric that emphasizes on spaces rather than buildings. They are built on human scale, streets are narrow and provide compound experience.City in the park: that usually is made of coarse grain (set of blocks) and emphasizes on buildings. Its convenience is for riders and provides monotonous experience. $\left[{ }^{2}\right]$ However total structure of city form is made of different levels that hierarchically and meaningfully deal with the whole of the city. The levels that are made of different patterns such as streets, blocks and lots. Urban blocks however constitute basic elements of urban form structure. $\left[{ }^{3}\right]$

Submission date: 17 October 2016

Lecturer at Islamic Azad university branch Shahrekord (m9heidari@gmail.com)
The Superblock is emerging as an integral solution to the use of public space, uniting urban planning with mobility, and limiting the presence of private vehicles in order to return the public space to the citizen. The importance of the citizen, or the simple pedestrian, gives meaning to the revolutionary structure of the superblock: each grid section has universal accessibility, there is increased safety due to a $10 \mathrm{~km} / \mathrm{hr}$ speed limit, and there is the potential to increase the habitability and comfort of citizens in public spaces.

The present research aims at exploring the results that huge blocks impose on their nearby historical fabrics both physically and spatially.. On the other hand however historical urban tissues are made of smaller pieces, and will represent more obvious results compared to those current urban blocks. Accordingly historical fabric of great mosque of Shahre-Kord chose as the case study (figure 1). The Theory of the study is that adjacency of historical tissue with a newly formed superblock, has led to degrading of its quality both physically and spatially and the trend is continuing. So that, analysis of present case can clear physical and spatial effects of these superblocks on valuable inner tissues of the cities.

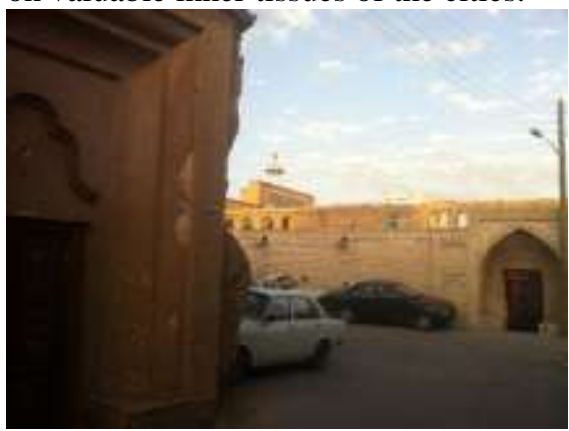

Fig 1: historical tissue of great mosque of Shahre-Kord.

(Superblock at the background). Source: author

In this research after problem statement and understanding necessity of addressing the issue, the importance of attention to superblocks as recent forms of cities will be emphasized. After representing background of similar studies, the study will address the literature of superblocks (generally) and factors affecting historical tissues sustainability. Ultimately in an adaptive comparison via observation, and Depthmap syntax software along with routs network analysis software of Pajek, the impacts of historical and superblock fabrics neighboring will be practically examined. Synthesis of the results of 
observations, images and videos along with software analysis will give some indication about the issue to be considered by local government in future development in the area.

\section{PROBLEM\& IMPORTANCE}

Chaharmahal-O- Bakhtiary Province having a rich natural as well as historical attractions and considered as important tourism hubs of Iran. However due to various reasons has not achieved its deserved tourist attraction spot yet. One of the reasons is lack of attention to remain valuable historical fabrics in the cities either by rapid construction of streets in the context of historical areas or by building coarse fragments in nearby. The issue has been raised during the history. As an example modernist ideas on one hand and need for rapid development on the other hand have led to streets historical patterns as well as urban space definition alteration. The process of redevelopment was highly disruptive to the economic and social infrastructure, while the product was also fatally flawed: large blocks simplified the land-use pattern, also diminished vitality and diversity of activities in those areas. $\left[{ }^{4}\right]$

This trend is rising in Shahre-Kord particularly about historical fabrics such as great mosque's tissue. The inhabitants of the historical tissue are not satisfied with the new developments around. The new neighboring block has larger size of a typical one (around 250 per 300 ) meters in addition, fine grain and great mosque historical fabric are not consonant either. It seems that some alternations has imposed on this urban fabric.

In terms of Importance, Generating of an urban texture commences with smallest elements the so called "plots". With multi plot assembly, a unit is shaped in higher level "block". The blocks are groups of plots, inscribed with some public streets and are result of incorporating forms and public spaces. $\left[{ }^{5}\right]$ Disregarding these new urban forms has led to some problems. As some of most significant urban problems in the past century and early of the twenty first have occurred in the places that new urban and architecture forms are built rapidly, in large scale, ignoring nearby urban fabrics. $\left[{ }^{6}\right]$ Because of being more sensitive context both physically and spatially also their economic and cultural importance if they maintain sustainability, the issue is important particularly in valuable fabrics.

On the other hand physical dimensions such as size, scale and proportions of a physical form in various levels of the city in which urban block is one of them, constitute one of the basic factors of place quality as urban design goal. (Sanders, 2008:2) indeed one of the ways of improving sustainability is to enhance the level of their preservation as high quality places. [ $\left.{ }^{7}\right]$ Research background

Although, no research has carried out to explore civic superblocks spatial/framework impacts on adjacent urban fabric (particularly historical fabric) yet, nevertheless some relatively comprehensive studies are being done about superblocks structure and their innate relationships.

One of significant researches which is relatively correspondent is Siksna's in 1991. He firstly tried to establish a comparative study among block forms in various historical sections (Greek, Roman, medieval and particularly in city centers of Australia and northern America within 17 to 19 centuries) in terms of form factors such as size and pedestrian movement patterns. Aftermath he explored relative performance of blocks and superblocks in city centers of Australia and North America in terms of noted factors. Regarding various forms of blocks he concluded that some urban block sizes are optimum and will impose minimum impacts on neighboring historical and typical fabrics. However he did not completely study the impacts.

The researches were carried out by architecture and urbanism department of Barcelona university has mostly explored the relation of arrangement and size of superblocks on urban transportation and energy consumption as well. The studies are mainly follow vehicle circulation within or out of superblocks and ignore other impacts.

Also Mattew Carmona et al (2003) studies in the definition of superblocks and brief description relating their changes through history published in the book "Urban spaces public places" are significant. After that (2004) historical samples of structural evolution of urban blocks have been brought by Philippe Panerai et al in the book "The Death and Life of The Urban Block". $\left[{ }^{8}\right]$

\section{LITERATURE}

\section{A. Urban block and superblock}

Urban block is a crucial and basic unit in every city. Its important role as a mediator of an area could not be ignored. It is highly resource as well as time consuming to make individual buildings in the city, however still the impacts imposed by the blocks that encircle these buildings is underestimated. A new kind of these blocks namely superblocks, physically compromise their surrounding context and implicate them with sea of vehicles by their scale and traffic they generate. In recent years notion of urban block design has found a significant spot. Numerous residential, commercial or mix use projects have built on block scale and street friendly development rather than massive individual buildings. They strengthen the relationship of various urban fabric levels (from lots to areas). As an apparent example, in California urban blocks are degrading or decomposing to an optimum size. $\left[{ }^{9}\right]$

In terms of physical considerations a superblock could be defined as set of basic routs that have formed a private and inner area within an urban fabric, similar to a cellule. The cellule of urban fabric includes 2 inner and outer component in which inner part typically bans entrance of strangers or restricts it and mainly is usable for settlers. The superblocks should be of high quality public spaces in inner as well as outer parts. Outer part also is the street by which superblock is inscribed. Perimeter of a superblock is about 400 per 400 meters. $\left[{ }^{10}\right.$ ] However it may not be possible to define an accurate size for superblocks since structure of a block or superblock is dependent on various factors. As Yoshida and Omae have maintained that form, size and number of buildings in each block, relates to their socio-economic functions. In other words, place and the size of a block is determined by function. [ 5]

Generally there is no unanimous definition for superblock. In addition to noted definition, Memidex dictionary defines 
superblock as an area of the city which is multiple size of a typical urban block and meets its own inhabitants commercial needs whether inside or around the superblock. Collins website on the other hand provides another definition: an urban area in which vehicle traffic is banned or limited, having mainly residential uses and rest of its uses include commercial, industrial and recreational. Still Keating et al [ ${ }^{11}$ ] state; an urban area that is larger than customary blocks, its buildings are bigger in size and usually is inscribed by main streets.

All definitions emphasize on the size of superblock by being larger than a typical urban block, meeting the needs of its inhabitant, having commercial as well as recreational activities and closed or limited vehicle traffic. All of the conditions exist within the present case study.

\section{B. Historic Fabric}

Improving material durability as well as exhaustion reduction in different ways is counted as significant ways of enhancing sustainability and preservation in historic fabric. $\left[{ }^{12}\right]$ the historic context preservation is carried out by minimum interfere or even frontage determination for valuable fabric, while in Middle East countries the approach may vary [6]

In general conservation is of much more narrowed meaning while applied to historic cities. It has 2 main roots:

1- Architectural conservation, whose starting points include archaeology and the geo-cultural diversity and historical evolution of architectural styles, building materials and techniques.

2- urban conservation: is townscape and a morphological and aesthetic approach to the management of change in historic cities.[7]

There are various alternatives to maintain a historical complex. According to the definition provided by historic heritage conservation organization of England, features of a historic building or fabric may divided into 4features:

1-Evidential Value: the feature of potential of a place to introduce evidences of the earlier people

2- Historical Value: the feature by which earlier people, events or various aspects of their life is connected to the present time through form of a place

3- Aesthetic Value: the feature that gives sense of simulation of the past to the people

4-Communal Value: meanings of a place for the people who connect with it. $\left[{ }^{13}\right]$

Accordingly, degradation or lack of one of the noted features will be obvious example of endangering historic buildings or fabrics. Aftermath it may be explored that which one of the features has been affected as a result of superblock and historic context adjacency.

Edussuriya et al (2009) state that the size of urban fabric grain will directly influence linear pollution of street and block scale as well. $\left[{ }^{14}\right]$ This impact is in form of a triangular relationship among linear pollution (street scale) and surface (urban fabric). Even the amount of persistence around an area is in direct relationship with the grain size of neighboring fabric. (fig.2). Wind current, temperature as well as pollution altogether are affected by grain size of urban fabric whether in the length, width and height.[14]
The size of an urban block could not only affect air circulation but also impose vehicle traffic to vicinity due to inner arrangement. The impacts of vehicle congestion is obvious. The more presence of vehicles, the less presence of pedestrian and social interactions.[4 ] (communal value).

In terms of perception of a historic fabric, with historic legibility in mind, vicinity of the two fabrics with similar size can result in legibility improvement. The issue comes to importance particularly when a new fabric is going to be constructed adjacent to a historic context. [8]

\section{STUdy AREA}

Chaharmahal-O-Bakhtiary province is located in south west of Iran at the center of Zagros Mountains. Having mountain weather Shahre-Kord is capital of the province while it is the highest city of Iran (known as roof of Iran). Downtown of the city that remains number of valuable monuments (historical buildings e.g. great mosque which is the only four-Iwan mosque of the province as well as historical bath of Khan, still several other monuments that refer to Qajar period altogether) form historical core of the city. The fabric of the compound composes of fine grain with twisting passes totally. Being old and center of the city, this area serves as a focal point of the socio-economic activities of the city, contributing to high level of vehicle and afoot traffic that has led to multiple importance. (figure 4)

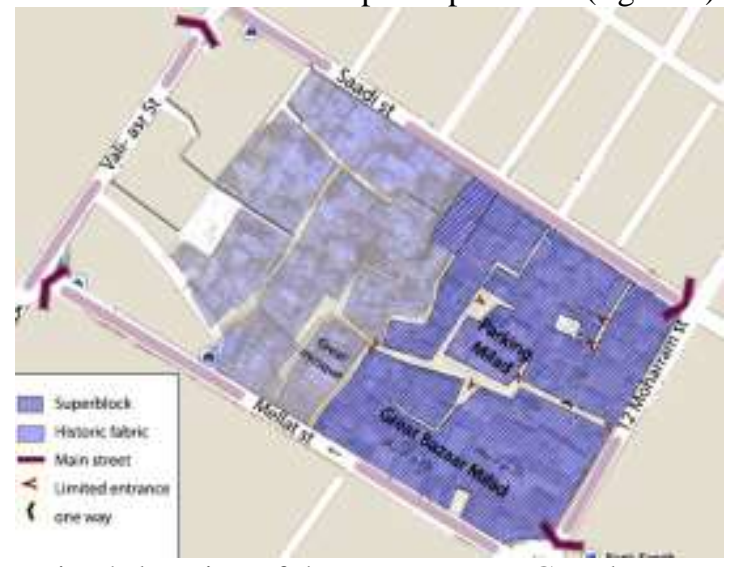

Fig. 4: location of the case, source: Google map

The area is located along Mellat St of which Mosharraf alley with heavy traffic access. Having antiquity of more than 150 years, most of the fabric materials are composite of brick and thatch.

During last 3 years, the nearby block has transformed to a multiple size of a typical one, by means of which physical permeability has reduced, overall height of building envelope has increased and converted most of inner alleys to one way or blinded. The changes commenced by the time, Parking and great Bazaar of Milad are constructed. Most of vehicle traffic and parking load however are made by inhabitants while outer vehicle traffic is dispersed to surrounding. It seems that this superblock has imposed some impacts on the nearby historic fabric. (figure 5) 


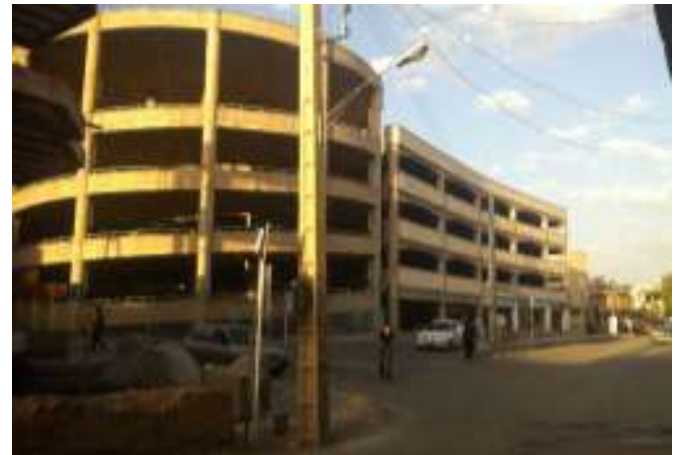

Fig. 5: Bazaar (right), parking Milad (left) in neighboring of historic context. Source: authors

\section{METHODOLOGY}

This paper was undertaken by analyzing Great mosque urban spaces using qualitative research methods. The main data collection is conducted using the "unobtrusive observational method', which tracks human behaviours in space through 'disguised field analysis'. Numerous repetitions of similar observations are undertaken at different times of the day and night in order to increase the validity of the results and given suggestions. The repeated behavioural tracking of the 2 selected public spaces of Manzarieh with different uses and activities are analysed based on 'evaluative observational variables' to ensure valid conclusions based on collected observations (Babbie, 1992; Brown, 2009). In the next phase the data gathered by observation, were analyzed more accurately by means of softwares "Pajek" (a network analysis software) and "Depthmap" (a space syntax utility) to explore physical spatial effects of the issue.

\section{RESULTS AND DISCUSSION}

The current section of the paper would look into the spatial behaviours within the nearby Great mosque public realm in order to identify indicators for pedestrian movement incentives. The selected public space is the most congested place in the area with Great mosque of Shahrekord located at the center.

By observation, public space no.1 seem to be "active" in terms of human activities with some of retailing premises along with Great mosque located here. Aside from being most accessible, the location of Great mosque behaving like a focal point for the area.

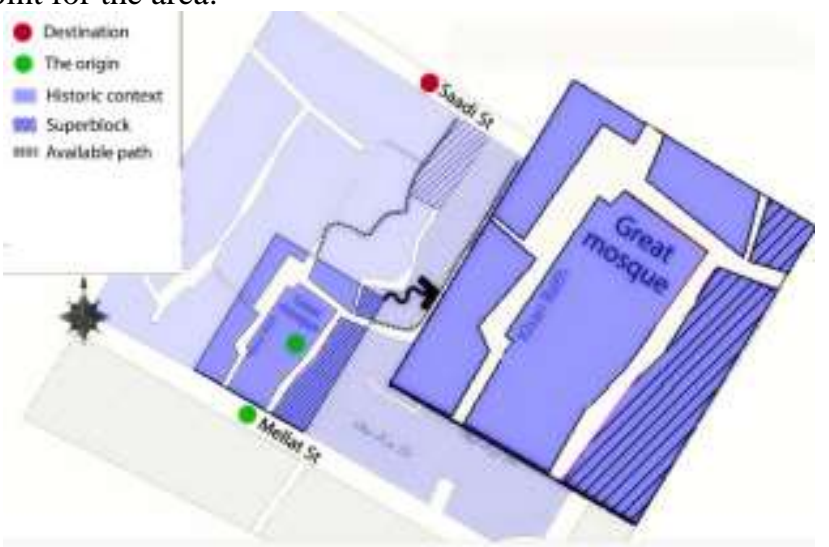

Fig.6: Selected public space for pedestrian movement analysis. Source: author

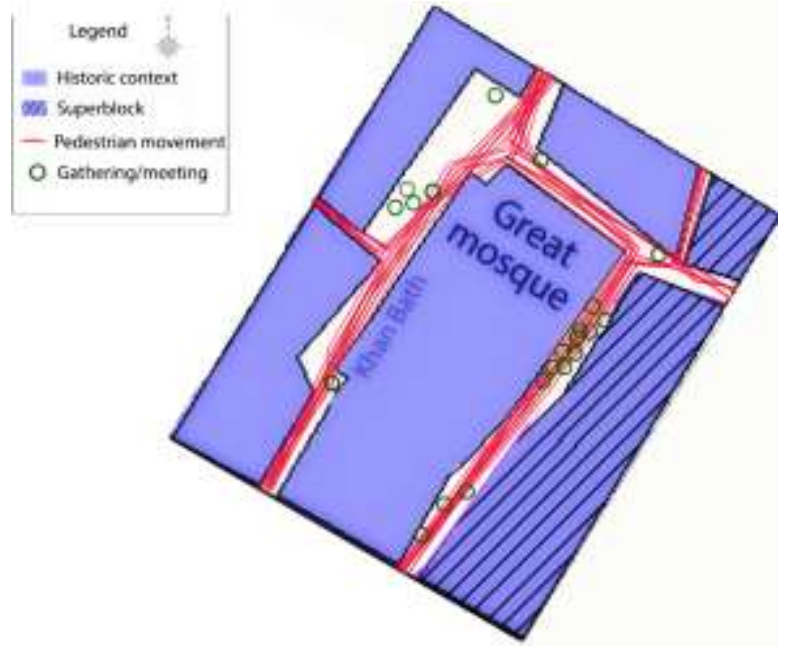

Fig.7: The pedestrian behavior analysis of the selected public space

The pedestrian movement pattern was obtained counting the moving people in each rout in five different periods a day and for five weekdays for each rout. $\left[{ }^{15}\right]$ The number of people interaction rises significantly near the Great mosque (center of historic fabric) especially in praying times. However the majority of gathering point (especially elder people) occurring in western and southern edge of the fabric where vehicle traffic coming from superblock decreases as illustrated in figure7.

Accordingly western routes of superblock (adjoining rout between block and historic fabric) act as transient rout. The same could not said about western routs with some traditional ceremony and religious mourning taking place in it (semi-public spaces)

Semi-public open spaces in which previously social interaction and various ceremonies once held are gradually converted to public part of streets, mostly parking lots. This way favorable quality of public spaces that is accounted as one of important features of superblocks either in or out of it has contributed to straight opposite, degradation of public spaces. (fig.8)

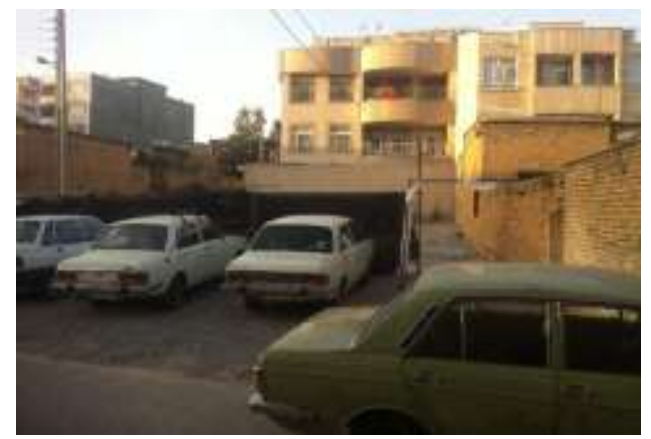

Fig.8: quality degradation of public spaces inside the historic fabric

Considering the origin and destination of pedestrian from Mellat St to Saadi and vice versa, most of the people chose western alleys of the site to pass through rather than eastern routs near superblocks despite less walking distance.

The movement towards the eastern side is the second least (after the nearer routs to superblock) and considered to be the place where people have the least integration with the 
superblock.

In terms of physical transformation, narrowing car crossover along with giving priority of movement to pedestrians is accounted as a ways of preserving historic context in Britain.[8 ] Not only observation but also Pajek analysis (as illustrated in figure 9 suggest that secondary routes around the superblock are emerging in favor of vehicle traffic in this case. No one of the passes crosses superblock as own. Particularly regarding the issue that historical fabric is a far easier way comparatively to the neighboring areas to be permeated through.

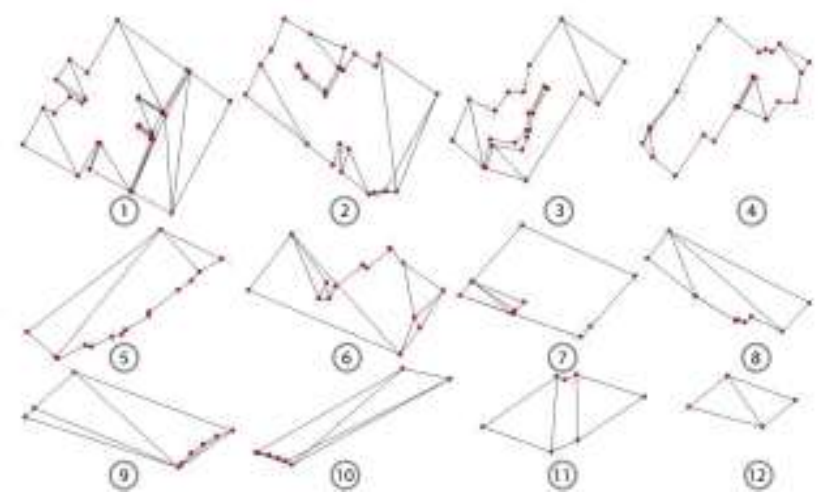

Fig.9: network transitions are illustrated in 12 steps. The more points in the form, the more transformation in the network as illustrated. Step 1 presenting number of break points in the tiniest level (inner historical network including alleys along with blind alleys). Aftermath it is getting more general scale by presenting alleys of the context. The procedure continues till the step 12 in which analysis network compose of 4 streets surrounding the block (the less breakpoints). Source: author

On the other hand observation suggest that material degradation of historic fabric was more highlighted in these parts of the context. This may be result of urban space scale pollution as noted in the literature. Air current is another change triggered by the new changes in the area. Monotonous massive wall of superblock which is located in direction of favorable wind serves as a physical blockage. (fig.10)

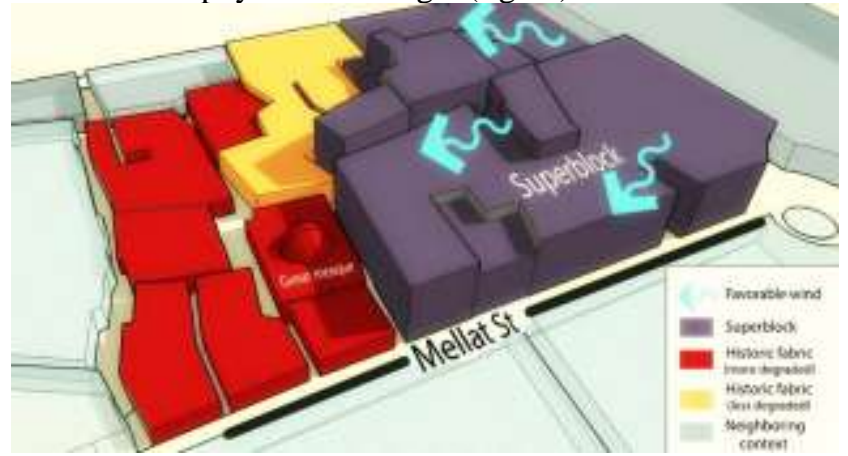

Fig.10: micro climate status analysis. The difference in material degradation level in various parts. Source:author

As being two of the 3 space syntax concepts (Convex space, Axial map and Isovist), we adopted Visual graph analysis (developed out of Isovist) and axial lines to illustrate spatial integration as well. Among VGA indexes, visual connectivity to get visual range from various points in public spaces is needed to explore which public spaces have more possibility to embrace pedestrian movements/gathering points.
It may be stated that in VGA, the zone is easier to reach from any networked spaces if Visual integration Value is higher. It is because pedestrians choose a route where integration value is higher. Figure11 (left) shows that linear space which connected Great mosque fabric and superblock corner had the highest value in general (260) compared to Great mosque back street with 256.

Figure 11 shows that many of large spaces which have wide range of view or crossings of passages have high Visual Connectivity (the range of 2-2045). The former is to be a waiting place and the latter is a junction of pedestrian flow. Such spaces were seen mainly in front of superblock and back of Great mosque spaces as illustrated in figure 11. For example surroundings of the Great mosque, and they were actually used as waiting places. (Despite higher VGA for superblock surrounding) On the contrary, low Visual Connectivity was seen mainly in north east alleys of historic fabric which had complicated configuration compared to those of superblock. Narrow view gives pedestrians negative effect in channel selection and reduces staying behavior in the space. This shows that pedestrians tend to gather in large space and visible range largely affects how pedestrians act.(mostly in High VGA value spaces of historic fabric, farther to superblock).

In terms of spatial integration $(\mathrm{HH})$, the graph shows the maximum value of 1.21 (with most integration and potential to retailers and other movement needed uses) for the main east west alley, connecting superblock and historical texture.

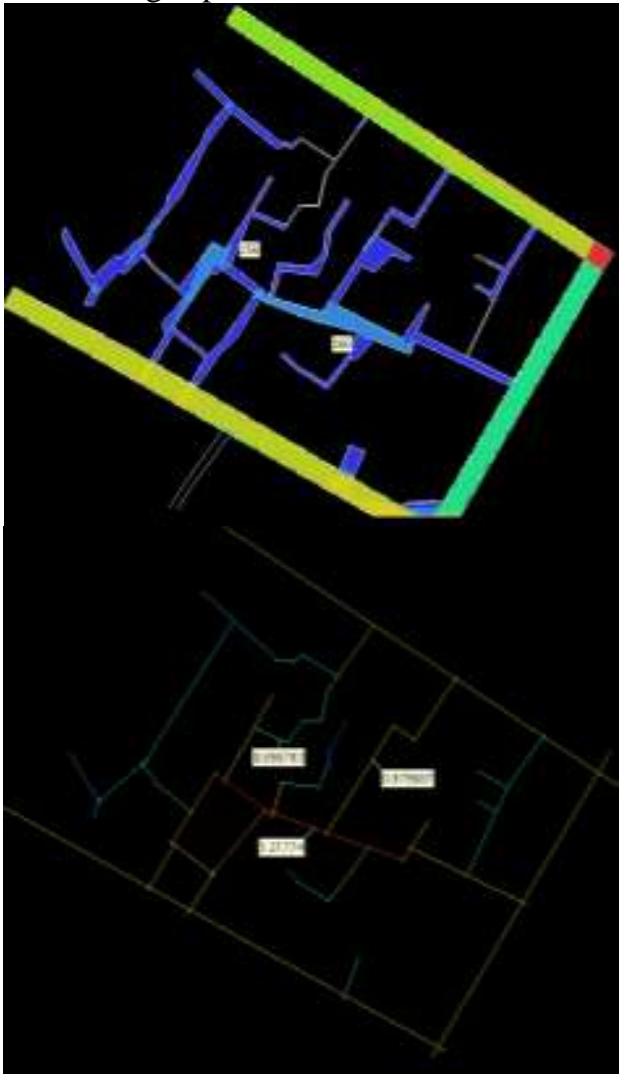

Fig.11: VGA analysis (up), Spatial integration analysis (down) of the area.

The physicality of the temporary space elements (Cars, temporary structures and so on) being in a middle of a busy and linear path (IV 1.21) creates a linear pedestrian movement with 
the least interaction between the temporary structures and the neighboring historical buildings. Such positioning and movement would also have the least socio-environmental impact on pedestrian behaviour and minimising the potential of the space as well. This intensified linearity converts the most integrated space of the area to act as a transient route rather than as an important path or node. A very similar layout has been seen on the other linear settings, especially those alleys nearer to the superblock, where similar impacts were observed. As a result, the balance between the stationary activities and the movement is not achieved; therefore possibilities of enhancing the identity of place are minimized.

\section{CONCLUSION}

In this study physical spatial impacts of superblock and Great mosque fabric adjacency were explored. It was revealed that transformation of spaces functions, has led to public spaces degradation quality of historic fabric due to superblock adjacency. Meanwhile not only the speed of transformations of network patterns has increased due to growth in number of breakpoints but also these changes have resulted in more vehicle congestion in nearest alleys of the superblock. Recording pedestrian movement pattern highlighted their preference of choosing farther alleys to the superblock rather than nearer. Legibility and expressiveness of historic urban texture is reduced due to contradiction between integration value and the real favorable spaces.

It may be noted that the present research has addressed physical as well as spatial aspects of the issue. The other aspects of this emerging issue is strongly proposed for future studies.

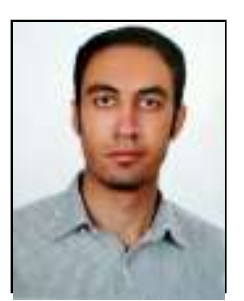

Milad HeidariSoureshjani Born at Shahrekord-Iran on $24^{\text {th }}$ april 1987 . Primary and guidance education passed in Shahrekord. Went to Islamic Azad university of Shahrekord with major in Architecture engineering. After graduating from Shahrekord university, he ranked $20^{\text {th }}$ on national university entrance exam and continued education in urban design field at Shahid Beheshti university of Tehran as Master degree. Working as Lecturer at Islamic Azad university of Shahrekord at the moment. HeidariSoureshjani, Milad (2015): Assessing impacts of using the gadgets on environmental preferences of urban space users Case study analysis of Jomhjouri Street and Mellat Park in Tehran, International conference on sustainable development, strategies and challenges With a focus on Agriculture, Natural Resources, Environment and Tourism, Tabriz, COI: ICSDA01_0200

- HeidariSoureshjani, Milad (2015): Theoretical debates on local vs global urban spaces, Emerging recent approach of Glocalism of urban spaces, 1st National conference on Geography, tourism, natural resources and sustainable development, written in Persian, COI: NCGTSD01_446

\section{REFERENCES}

[1] Evans. R. (2005) Urban Morphology: The Handling Characteristics of Urban Form, Urban Design, Winter 2005, Issue 93, PP: 7

[2] Schumacher. T. (1996) Contextualism: Urban Ideals and Deformations, in theorizing a new agenda for architecture, kate Nesbitt ed, Princeton, Architectural press.

[3] Edussuriya. P,Chan. A,Ye. A. (2009) Urban Morphology and air Quality in Dense Residential Environments in Hong Kong. Part1, Atmospheric Environment 45, 4789-4803, PP: 2

[4] Carmona. M. Heath. T, Oc. T, Tiesdell. S. (2003) Public Places Urban Spaces: The Dimensions of Urban Design, Architectural Press, PP: 31
[5] Hermosilla. T,Ruiz.L, Recio. J, Cambra. M. (2012) Assessing Contextual Descriptive Features for Plot-based Classification of Urban Areas, Landscape and Urban Planning 106,124-137, PP:2

[6] Larkham. P. (2011): Wrote on Understanding Urban Form?, available at: www.Rudi.net

[7] Rodwell. D. (2007) Conservation and Sustainability in Historic Cities, Blackwell Publishing

[8] Panderai. P, Castex. J, Depaule. J, Samuels. I. (2004) Urban Forms: The Death and Life of The Urban Block, http://books.elsevier.com

[9] LARPHG. (2013) The Use and Abuse of The Urban Block, Presented by the Los Angeles Region Planning History Group, North Hollywood, CA 91602

[10] Barcelona Urban Ecology Agency (BUEA) (2010) Superblocks: An Instrument for Open Space Improvement, BCN Ecologia Press

[11 ] Keating, W. Dennis, Norman Krumholz (2000). "Neighborhood Planning". Journal of Planning Education and Research 20 (1): p. $111-114$

[12] OHP. (2012) Sustainable North Park Main Street Report, available at: www.Northparkmainstreet.com/

[13] English Heritage (2008) Conservation Principles, Policies and Guidance, available at: www.English-Heritage.org.uk

[14 ] Edussuriya. P,Chan. A,Ye. A. (2009) Urban Morphology and air Quality in Dense Residential Environments in Hong Kong. Part1, Atmospheric Environment 45, 4789-4803, PP: 2

[15 ]Hillier, B., A. Penn, J. Hanson, T. Grajewski, and J. Xu. "Natural Movement: Or, Configuration and Attraction in Urban Pedestrian Movement." Environment and Planning B: Planning and Design, 20 (1993): 29-66. 